\title{
Consideration on Factors Related to Athletes' Mental Toughness
}

\section{Shogo Komatsu*, Satoshi Yoshinuma, Chieko Kato, Koichiro Aoki}

Faculty of Information Sciences and Arts, Toyo University, Kawagoe, Japan

Email: *komatsu200@toyo.jp

How to cite this paper: Komatsu, S., Yoshinuma, S., Kato, C., \& Aoki, K. (2021). Consideration on Factors Related to Athletes' Mental Toughness. Psychology, 12, 595-606.

https://doi.org/10.4236/psych.2021.124037

Received: March 15, 2021

Accepted: April 22, 2021

Published: April 25, 2021

Copyright $\odot 2021$ by author(s) and Scientific Research Publishing Inc. This work is licensed under the Creative Commons Attribution International License (CC BY 4.0).

http://creativecommons.org/licenses/by/4.0/

\begin{abstract}
It is essential for athletes to achieve a strong mental attitude in order to perform to their potential in matches and other contexts. Previous studies that have looked at the nature of a strong mental attitude have raised the issue of mental toughness, and it is thought that improving this is extremely important. However, few research studies as yet have made clear what type of psychological structures athletes with a strong mentality possess. Therefore, in this study, we conducted an interview style survey about mental toughness of 20 university student athletes who were competitively active either during or before their school years, in order to uncover the psychological structures behind athletes whose strong mental attitude enables them to perform to their potential in matches and practice. We conducted a qualitative examination about the psychological mechanisms of athletes with a strong mental attitude from the ensuing linguistic data. As a result, we found that the qualities of "willpower" and "control" enabled athletes to overcome immediate and frequent issues, while "recovery from difficulties and subsequent growth" meant that they were able to recover from events considered to be difficult to overcome, and that these factors are largely what constitute mental toughness. In addition to "willpower" and "control," a lot of respondents mentioned factors in the interviews that have rarely been dealt with in our conception of mental toughness up until now, such as interpersonal relationships and the presence of others, suggesting the ability to trust oneself and others (or "sociability") is also a key factor that constitutes mental toughness. It is also hypothesized that the factor of positivity, the ability to view one's way of life up until now and the future in a positive light, as well as an optimistic approach to life, are also important factors in mental toughness. Furthermore, it has been shown that possessing a strong mental attitude is also related to an athlete's psychological traits, as well as past and present interpersonal relationship styles.
\end{abstract}




\section{Keywords}

Mental Toughness, Athlete, Interview

\section{Background and Purpose of This Study}

Athletes are required to perform to their maximum potential, and being able to do this without being affected by the pressure of competition and difficulties is thought to be the mark of an athlete with a strong mental attitude.

Mental states such as "anxiety," "mental strain" and "stage fright" are examples of the pressure competition can exert on an athlete, which can inhibit their ability to perform to their potential (Murayama \& Sekiya, 2012). According to Fukui et al. (2014), in research conducted around the relationship between "anxiety" and performing to athletic potential in university athletes, the psychological state of athletes had a significant impact on their competition performance.

However, Horikawa and Yagi (2007) state that "anxiety can facilitate performance, or conversely, inhibit it," and anecdotally, there are examples of "anxiety" and "mental strain" aiding an athlete's performance. It is thought that an individual's own psychological traits are largely what decide whether this "anxiety" and "mental strain" can be harnessed in order to perform to their full potential.

Injuries are a typical example of a difficult event faced by athletes, with many sustaining injuries either during competitions or in their everyday lives. As Suzuki \& Nakagomi (2013) state, these injuries can often lead to a loss of desire to compete, as well as increased feelings of isolation and despondency, with some athletes feeling forced to retire.

Actual performance can differ greatly depending on how an athlete recognizes and copes with pressure and difficulties, and athletes who can perform to their maximum potential are thought to be equipped with a strong mental attitude.

As a result, in recent years, there has been increased conversation about the importance of mental training alongside physical training, and the improvement of an athlete's "mental strength," which is linked to better performance not just at the time of competition, but also in practice and within everyday life, can be seen as an important topic. When looking to improve an athlete's "mental strength," it is essential for those supporting the athlete and the athlete themselves to have a thorough understanding of the psychological traits and psychological structure of athletes who have a strong mental attitude.

However, the concept of "mental strength" is extremely vague, and even in previous studies about past athletes, there has been a great deal of research into this concept. Various interpretations of the definition and constituent factors of "mental strength" have been advocated, yet there is still no unified view presented as an integrated theory.

Tachiya (2018) conducted an interview study of seven top athletes and asked questions about mental strength such as, "What psychological factors and traits 
do you think top athletes require? Please include factors outside of a competition scenario," and, "Why do you think those factors and traits are necessary? Please give concrete reasons." Answers such as "not being influenced by others," "having a strong sense of self," and "feeling centered in myself," showed the importance of an independent attitude, while responses describing the psychological factors necessary for competitive situations were also received, such as "not feeling the pressure," "a strong desire to win," "determination," "fighting spirit" and "confidence."

Takekawa et al. (2017) used the Diagnostic Inventory of Psychological Competitive Ability (DIPCA.3) in research comparing athletes with experience of national level competitions and those without, and found that, in particular, the "ability to control oneself" scored significantly higher marks. This can be seen as consistent with the previously mentioned trait of "not being influenced by others," leading one to assume that one element of a strong mental attitude is being able to control one's own mind and body.

The results of these studies show that there is no one psychological trait displayed by athletes with a strong mental attitude, but rather a variety of characteristics. There is a further need to explore what factors comprise the expansive concept of "mental strength," and how these factors relate to each other.

The concept of "mental toughness" has been proposed in previous studies in recent years, mainly in Europe and the States, as a concept related to this "strength of mind" (Loehr, 1982). The concept is often illustrated as the factor for athletes to demonstrate their abilities. For instance, Jones et al. (2002) state that "generally, it (mental toughness) is the ability to meet the many requirements that sports impose on performers (competition, training, lifestyle) better than their opponents. Especially, it is the better consistence so the sport players can be more determined, focused, confident, and perform under pressure."

In the theories about mental toughness, there are attempts to quantify the toughness of subjects such as the representative Mental Toughness 48 Inventory (MT48) based on the 4Cs model upheld by Clough et al. (2002). Four factors are listed in the model as the factors of mental toughness, which are "Control" (referring to self-esteem; the extent that one feels under control of life and situations. Also, more importantly, the range to control the expression of emotions), "Commitment" (referring to the "determination to strike for the goal", the extent that one sets a goal and is ready to make a measurable promise to work hard to achieve it), "Challenge" (the ability to accept changes and risks; the ability to see threats as chances to enjoy learning and growing in uncertainties), and "Confidence" (the belief to complete the big picture, explanation of self-belief that individuals have and the interpersonal faith to influence others and deal with conflicts and challenges.)

Concepts similar to this theory of mental toughness include the concepts of "hardness" and "resilience". First, "hardness" is defined as "personality traits that function as stress-tolerant resources in stressful life events" (Kobasa et al., 1982). When we put this concept of hardness into the captioned 4Cs model by 
Clough et al. (2002), it is equivalent to "Control", the ability to keep one's mental state constant, and "Commitment", the ability to push toward a goal indeed.

"Resilience" means the ability to recover from heavy stress, threats, and trauma then move forward (Neil, 2003), the exposure to difficult situations and falling into a negative psychological state but still, does not result in a serious psycho-pathological state, or the individual psychological rebounding ability (Mutou, Mori, Endo, \& Tamase, 2004).

Based on the overview of previous studies on the elements that make up this concept of "resilience", it is related to "sociality" (the ability to coordinate with other even under undesirable situations) and "social support" (the ability to constitute a network to attain support from others) that the ability to acquire help from the surroundings is often described as one of the components of "resilience". They often consist of elements that reflect the level of interpersonal relationships similar to the above captioned "social support" and "sociality" as also reflected in other theories about resilience (Satou \& Sukemune, 2009). Furthermore, Hirano (2014) also touches on the huge influence of "reliable people" and "people to talk to" as the essential elements to breakthrough difficult situations. Considering all these, it is not simply internal ability when we think of the concept of mental toughness but interpersonal relationships and skills such as how well one can utilize the support from others to grow, these are also closely linked to mental toughness. Nevertheless, the number of studies touching on these interpersonal factors when focusing on the mental toughness of athletes is very limited. It is crucial to consider the way athletes possess interpersonal relationships and how their internal self-image and other-image influence "mental toughness."

Based on these previous studies on mental toughness, it is conceivable that "mental toughness" is a concept that combines "ability to overcome" like hardness and "ability to recover" as mirrored in resilience. Yet, the number of studies examining the mentality of athletes with excellent performance are limited that the presentation of theoretical hypothesis about the psychological structure of a mentally strong athlete would be extremely significant in studying effective mental support for athletes.

As illustrated, when we think about mental support for athletes to demonstrate their abilities, it is vitally important to evaluate individual psychological features of athletes. In order to improve mental toughness according to individual features, it is essential to reveal what the "strength of mind" of top athletes is.

When creating a theoretical model in any field, it is necessary to consider research methods. Research that seeks to empirically explain natural and social phenomena can be divided into research that deals with quantitative data and research that deals with qualitative data. To conduct quantitative research, it is necessary to have extracted ideas from within previous studies related to the topic of the research, and if research has yet to produce results to that level, it is then that qualitative research is undertaken (Saiki, 2014). There is little research that has attempted to clarify the conceptual model of the subject of this study, 
"mental toughness", so in order to create a theoretical model, it is necessary to start creating a model through qualitative research. Ultimately it will be necessary to verify the suitability of the model again using quantitative data based on this theoretical model.

One method of creating a theoretical model such as is seen in the KJ method (Kawakita, 1967) and others is to extract concepts from data derived from linguistic information, link in similar concepts, create one over-arching higher category, and attempt to produce a visualization that displays that inter-connectivity. The advantage of this method is that it can reduce the risks presented by analyst bias, as it is carried out in stages by several analysts. Also, by displaying information visually, it becomes easier to share the results of the research with others, as the ideas analysts have can be shown in an accessible visual format. It has the further advantage of allowing individuals to transcend their own normal way of thinking and arrive at ideas that would be hard to come up with, through the process of considering the connections between categories. Typical examples of qualitative research methods include the aforementioned KJ method, grounded theory approach, content analysis and SCAT.

Using previous qualitative analysis methods as a reference, this study will look at the expansive concept of "mental strength" as required of athletes (also referred to as "mental toughness"), aim to ascertain what mental strength is comprised of, and establish how this is related to an individual's psychological traits and the environment that surrounds the individual, by conducting semi-structured interviews with athletes who have achieved great results and collecting the resulting linguistic data. If this study is able to produce a hypothesis on the components that comprise mental toughness, then we feel it can become an important guideline when drafting support goals for psychological support including mental training.

\section{The Aims of This Study}

This study aims to ascertain the psychological traits of athletes with a strong mental attitude through the consideration of athletes who have been active in official competitions from early childhood to inter-high school. Specifically, we conducted an interview study of university student athletes and asked questions related to mental strength, with the aim of establishing the characteristics of athletes with a strong mental attitude and the components related to the formation of mental toughness.

\section{Research Method}

In this study, we conducted semi-structured interviews with athletes who belonged to university baseball, rugby and track and field clubs and who have a history of achieving great results in competitive activities. We did this in order to establish the characteristics of the mental toughness possessed by athletes with a strong mental attitude, as well as identify the factors that are key to improving 
mental toughness.

\subsection{Interview Timing and Location}

The interviews were conducted in December 2020 in a university laboratory. An online conference system (Webex Meetings) was used in cases where participants were unable to attend in-person interviews.

\subsection{Participants}

The participants in this study consisted of 20 male students from A University who belonged to its hardball baseball, rugby and track and field clubs, and who have achieved great results in their athletic activities, such as competing at an inter-high level or being selected regularly to participate in official competitions.

\subsection{Interview Procedure}

When conducting the interviews, a researcher explained the content and ethical considerations of the study to the participant, and obtained consent from the participant before starting the interview. The statements made by the researcher and the participant were recorded using a voice recorder or the record function of Webex Meetings. There were four sections of questions asked in the semi-structured format of the interviews, which were, "questions about attitudes to mental toughness," "questions about what comprises mental toughness," "questions about life experiences and future prospects" and "questions about self perception" (Table 1).

\section{Results}

The responses given by the participants in the interviews were transcribed, then placed into 14 different categories, after which a category related diagram was then created based on these classifications. The 14 categories were as follows: 1) Understanding of mental toughness; 2) Knowledge and practice of improving mental toughness; 3) Experience of and desire for mental training; 4) Influencing events and people; 5) Recovery from difficulties and subsequent growth; 6) Willpower; 7) Control; 8) Sociability; 9) Positivity; 10) Daily endeavors; 11) Visions of the future; 12) Personality and way of thinking; 13) Communication skills. The above categorization process was carried out by a group of three researchers which included experts in the field of psychology.

First, we created the categories of "understanding of mental toughness" and "knowledge and practice of improving mental toughness," based on the responses we received under the section of "questions about attitudes to mental toughness," and decided to take this as a definition of "mental toughness."

We then created the categories of "willpower," "control," "sociability," and "positivity" based on the responses we received under the section of "questions about what comprises mental toughness." 
Table 1. Interview: Question items.

\section{[Questions about attitudes to mental toughness]}

- Understanding of mental toughness: What does “mental toughness" mean to you?

- Knowledge and practice of improving mental toughness: What methods do you think could be used to become tougher mentally?

- Experience of and desire for mental training: Do you have any experience of mental training? If so, could you talk about it?

[Questions about what comprises mental toughness]

- When do you feel motivated about something? What do you usually do to keep motivated?

- How do you change the way you feel when you make a mistake?

- Are there times when you feel supported by your family? What aspects do you feel supported with?

- How fulfilled or satisfied do you feel about your life up until now? If so, what aspects have made you feel fulfilled or satisfied?

[Questions about life experiences and future prospects]

- Have there been any events that you feel have had a big impact on your life? How do you feel it affected you?

- Of the difficult events and adversity you have faced up until this point, which was the most painful? How did you overcome it?

- What have you done to achieve your goals, and what are you doing currently?

- What are your current goals and dreams? What are you doing to achieve them?

\section{[Questions about self perception]}

- Are you someone who can withstand pressure, anxiety and mental strain? If so, through what experiences have you been able to develop the ability to do that, in your opinion?

- Is there anything you are careful of when expressing your opinions or feelings to the people around you?

- Challenges and strengths: What do you think you need and what things would you like to overcome?

We created the categories of "influencing events and people," "recovery from difficulties and subsequent growth," "daily endeavors" and "visions of the future" based on the responses we received under the "questions about life experiences and future prospects" section.

The categories of "personality and way of thinking," "communication skills" and "challenges and strengths" were created based on the responses we received under the "questions about self perception" section.

We discussed the connections between these 14 categories and drew up a category relationship diagram, which can be seen in Figure 1. Included on the diagram are examples of responses that relate to each category. 
Definition of mental toughness

\begin{tabular}{|c|c|}
\hline $\begin{array}{l}\text { 1. Understanding of mental toughness } \\
\text { ense of calm: "I think toughness is connected } \\
\text { to maintaining your own state of mind and } \\
\text { emaining calm no matter what the situation." } \\
\text { In critical situations: "Resisting anything self - } \\
\text { defeating. It happens in critical situations, } \\
\text { because I'm a pitcher, like when practice is } \\
\text { tough, or in matches." } \\
\text { xperience: "You can improve through training } \\
\text { perhaps, but mainly, it's probably experience. } \\
\text { Because everyone is different, and so are the } \\
\text { situations and environments. You just have to } \\
\text { experience it." }\end{array}$ & $\begin{array}{l}\text { 2. Knowledge and practice of improving mental } \\
\text { toughness } \\
\text { Introspection: "After the match, I try to look } \\
\text { inwards and reflect on not just the good parts but } \\
\text { also the bad ones." } \\
\text { Participation in competition: "Mentally strong } \\
\text { people are able to produce results, so to get } \\
\text { those results, you have to practice everyday and } \\
\text { have the strength to keep going. I do what I think } \\
\text { is necessary, and if it works out, then I'll do it for a } \\
\text { week or two weeks, a month or two months, then } \\
\text { before I know it I've been able to do it for a year." }\end{array}$ \\
\hline
\end{tabular}

\begin{tabular}{|c|} 
5. Recovery from difficulties and subsequent growth \\
Experience of injury: "I feel like, if I hadn't been injured, \\
I wouldn't have been able to grow." \\
Opportunities: "I've taken opportunities and become \\
stronger. I've taken chances, like, 'I'll make the decision!' \\
or 'This is where I'll hit it!', that kind of thing, and gotten \\
stronger, and become able to enjoy opportunities. I \\
think I started to enjoy it in university, but when I was in \\
high school, I would stand up to bat, with the thought \\
that I was the one making the decision. I think that's \\
where that part of me really grew."
\end{tabular}

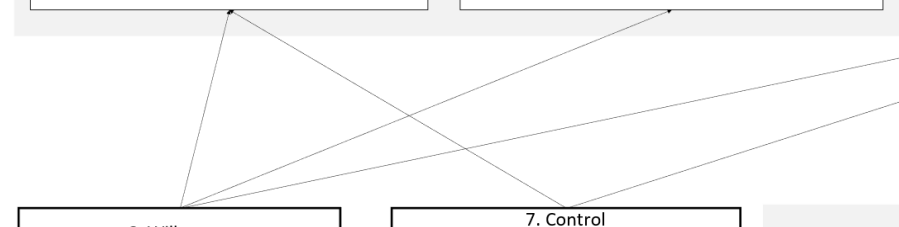

6. Willpower
Goals: “It's strange to say that you
can't try your best if you don't have
goals, but I think that if you do,
you're a lot more motivated, even in
practice. I always try to have a goal in
mind."
Ambition: "From when I was small
my dream was to be in the Olympics.
That was my goal, and through that
process, that started at a young age, I
was crowned champion in
competitions. Even now, my goal is
the Olympics. Whenever I see my
seniors, who have experienced
competing in the Olympics, I feel
even more motivated."
Practice: "It's just me, so I practice,
talk to my coach, try things out. It's
trial and error. The more I do, the
more confidence I have."

Switching from one thing to another: "I switch on and off quickly. When I'm doing something, I do it right, and when I'm not, I don't do anything." Objectivity: "It's not just about concentrating, but also having a clear concentrating, but also having a clear
view of your surroundings, and focusing on the race itself. It's something I really value."

Emotional control: "It's not cool to expose your emotions. While it's fine to every now and then, I think it's better to keep a lid on them and sort them out, for yourself and for those around you Keep it to yourself, calm down, and think."

\section{Daily endeavors}

Lifestyle habits: "I live an ordered life." "I make sure to wake up properly, and to catch some rays."

Information gathering: "I have done a fair bit of soul searching within myself, but I think maybe I've not been doing enough, I'm lacking in knowing about my opponents, and studying the opposing team. There's probably more to be done on that front."

Continuity: "Keep doing one thing, and do it everyday. I learned the importance of continuity in high school. That's what

\section{Trust}

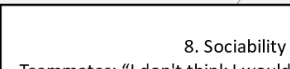

Teammates: "I don't think I would be able to do it if didn't ever do it for my teammates. Just being there is enough to make me feel supported."

Friends: " Right, friends... They come and support me...That's where they come to support me." Family: "I' $m$ in touch with my parents frequently, to say how I'm doing, and they tell me to keep going and do my best. They always have something positive to say." Coach: "I feel so grateful for being able to play baseball all this time. I'm grateful to my coaches too, for treating me well, no matter what the situation."

4. Influencing events and people Parents: "When I was deciding my career path, and thinking through various things, they didn't say anything, though when they later said, "I thought you'd go there," I fe like they had guided me really well. Teachers: "My elementary school coach. That's where started playing the basics. That's where by basics the basics. that s where by base is. wanted to be a pro from elementary school onwards." "he head of $\mathrm{my}$ rugby. I feel like he has been around my whole life."
9. Positivity Enjoyment: "During a match. Baseball is fun. I can play against various different batters."

Challenge: "When I try things that other people find impossible or difficult.

It doesn't affect me if eople laugh at my mistakes. I want to do what I want to do."

Fulfilment: "When you do the same thing in practice, and you overcome it, thin like that, ar it's the same like that, a soit's the same when we win. When you're working really hard, you tal to each other and you've done your best. That's when I think, wow, this is really rewarding."

\section{Experience of and desire for mental} training

Routine: "I have a routine of going to bed with a positive mental image instead of anxious thoughts, and I do that whether it's before a match or before practice." Having a goal: "I don't know if it's mental training or not, but when I was in high school, I remember writing out on paper all the steps I needed to take to achieve my goal."

Yoga: "Yoga? Yes. I also do breathing exercises. There are times when I feel like I'm struggling, so it's then that I really focus on my breathing."

\section{I've tried to do." \\ }

11. Visions of the future Image of the ideal player: "I want to be a player and person loved by the fans." Image of the ideal person: “I don't need to stand out, but it would be cool if people thought, 'I happened to notice he was there,' or 'That guy's pretty big,' about me." "As a human being, I think the best kind of life is one where the the best kind of happy times continue. How happy do happy times continue. How happy do
you think you are with that? Can you you think you are with that? Can you
make other people happy? I want to be the kind of person who can think like that."
13. Communication skils Understanding others: "I try personatity was in used to think, wow, this really in this dorm, and I think, there re so many different types of people. Even if they think differently, they know about me too, and they can also know that there are people like me."

Figure 1. Category related diagram.

\section{Results}

The factors of the athlete's strong mental abilities were revealed after those with strong mental abilities were interviewed based on what is thought to be related to "Mental toughness". 
It is thought that strong mental strength requires [willpower] such as "The ability to complete daily practice" and "The power to push forward to future goals" which is indicated by responses like: [If I don't have a goal, it would be strange if I couldn't do my best, but if I had one, it would be more like practice and motivation. I always try to have a goal.] [Using my own methods and asking to my coach I practiced through trial and error. The more I did, the more confident I became.]

Also, the ability to control one's own mental state such as "Make decisions and take action calmly", "The ability to maintain a normal state of mind at all times" and "the ability to concentrate at the right moment" are reflected in the next answers: [I can switch On and Off quickly, and when I do, I do it right, but when I don't, I don't do anything.] [I think it's better for me and others if I keep things under control and think calmly.]

These strengths can be considered to correspond to traditional hardiness, which is the [Power to overcome]. According to Igarashi et al. (2006) and others, hardiness consists of three components: commitment, control, and challenge. Commitment is "the tendency to feel committed (involved) in various areas of one's life", control is "the degree to which one perceives that events in one's life are controllable" and challenge is defined as "the tendency to view unexpected changes or potentially threatening situations as positive challenges for future growth rather than as harmful events" (Kobasa, 1979; Kosaka \& Yoshida, 1992). Considering the correspondence between these concepts, "willpower" can be considered to correspond to commitment and "control" to control.

It is considered that not just motivation and control over daily practice and competition matters for athletes with strong mental abilities, the power to recover from injuries and setbacks [Recovery and growth from difficulties] such as [the power to turn a tough situation into an opportunity] and [the ability to turn the unexpected, like an injury into experience] are also important. A similar concept to resilience, has traditionally been proposed to be related to mental strength.

In addition, among the questions about mental toughness, some of the most notable statements made by the participants were many references to the people around them and others they had interacted with in the past. This interpersonal factor is one of the crucial components of mental toughness. [I think it's absolutely impossible without something like do it for my partners. I feel that their existence alone is quite supportive] [Well, my friends come to cheer me on] [I keep in touch with my parents, and when talk to they my situation, I feel can do my best. They always give me positive words.] [I am very grateful to have been able to play baseball so far. I am grateful to the instructor for being able to always treat me properly.] The concepts obtained from the answers regarding these interpersonal relationships were "influential events/persons", "social skills" and "communication skills". We decided to capture these in the category of [Trust in oneself and others] this category is thought to be related to reciprocal 
interaction and to the "personality/way of thinking", "challenges and strengths" concepts that are a reflection of the individuals psychological characteristics.

In addition, experiences of being influenced by people and receiving help from others have influenced the "About the future image" section, where responses such as [I want to be a respected person] were obtained. It is thought that the ideal image of the self that has been internalized from others, forms a structure that influences the current willpower.

The mental training in the concept of "experience and desire for mental training" is thought to have an impact on the psychological characteristics of individuals and the improvement of their willpower and control. The daily routine and regularity of life, as reflected in "daily efforts," are thought to be interrelated with the ability to control.

\section{Summary and Future Assignments}

In this study, we interviewed athletes with strong mental abilities who can demonstrate their abilities in games and performances about mental toughness and tried to construct a hypothesis about the factors that constitute mental toughness by illustrating the relationship between the concepts that constitute mental toughness.

As a result, it became clear that mental toughness, which is the power necessary to demonstrate one's abilities, is largely composed of the power to deal with matters in front of one's eyes on a regular basis, as reflected in "willpower" and "control" and the ability to recover from events that seem difficult to overcome, as reflected in [recovery and growth from difficulties].

In addition to [willpower] and [control], the four previously assumed factors of [trust in oneself and others], [positivity] including the [social skills] were thought to be related to this resilience. It was also thought that the psychological characteristics of the individual, the ideal image formed from past relationships with others, and the style of behavior by mental training and daily life also influenced mental toughness through [willpower] and [control].

By attempting to construct a theoretical model of the relationship between these concepts, it was possible that individual psychological characteristics, past and present interpersonal styles, and experiences may indirectly influence mental toughness.

Finally, although there have been many theories on mental toughness, few have attempted to construct a theoretical model using qualitative analysis, so this study is significant in that sense.

Currently, the future assignments are to continue collecting psychological data on college student athletes and to conduct quantitative research on the model constructed in this study to verify the validity of this model. Also, the survey respondents in this study were only college student athletes, and the future work should include cross-sectional comparisons of younger and adult athletes to determine whether model structure changes with age. 


\section{Conflicts of Interest}

The authors declare no conflicts of interest regarding the publication of this paper.

\section{References}

Clough, P. J., Earle, K., \& Sewell, D. (2002). Mental Toughness: The Concept and Its Measurement. In I. Cockerill (Ed.), Solutions in Sport Psychology (pp. 32-46). London: Thomson Learning.

Fukui, K., Tsuchiya, H., \& Toyoda, M. (2014). Anxiety, Competitive Ability, University Student-Athlete, Psychological Competitive Ability. Bulletin of Biwako Seikei Sport College, 11, 71-77.

Hirano, M., \& Umebara, S. (2014). A Systematic Review to Understand the Innate and Acquired Aspects of Resilience. Bulletin of Tokyo Kasei University, 58, 61-69.

Horikawa, M., \& Yagi, A. (2007). Psychophysiological Changes and Performance under Pressure in Sport. Kwansei Gakuin University Repository, 57, 47-60.

Igarashi, Y., Nakano, M., Nakatani, T., \& Moriyama, M. (2006). Development of the Japanese Health-related Hardiness Scale. Journal of Japan Academy of Nursing Science, $26,13-21$.

Jones, G., Hanton, S., \& Connaughton, D. (2002). What Is This Thing Called Mental Toughness? An Investigation of Elite Sport Performers. Journal of Applied Sport Psychology, 14, 205-218. https://doi.org/10.1080/10413200290103509

Kawakita, J. (1967). Way of Thinking: For Creativity Development. Tokyo: Chukoshinsho.

Kobasa, S. C. (1979). Stressful Life Events, Personality, and Health: An Inquiry into Hardiness. Journal of Personality and Social Psychology, 37, 1-11.

https://doi.org/10.1037/0022-3514.37.1.1

Kobasa, S. C., Maddi, S. R., \& Kahn, S. (1982). Hardiness and Health: A Prospective Study. Journal of Personality and Social Psychology, 42, 168-177. https://doi.org/10.1037/0022-3514.42.1.168

Kosaka, M., \& Yoshida, S. (1992). Relationship of Personality Hardiness, Stressor, and Psychological Health: Study of Executives. Studies in Sociology, Psychology and Education, 34, 43-50.

Loehr, J. E. (1982). Athletic Excellence: Mental Toughness Training for Sports. New York, NY: Plume.

Murayama, T., \& Sekiya, H. (2013). Factors Related to Choking under Pressure in Sports and the Relationships among Them. Japan Journal of Physical Education, Health and Sport Sciences, 57, 595-611.

Mutou, T., Mori, T., Endou, Y., \& Tamase, K. (2004). Psychology (pp. 184-189, 437-441). Tokyo: Yuuhikaku.

Neil, S. E. S. (2003). Enhancing Family Resilience: A Transgenerational Approach to Positive Change in Dysfunctional Families. In E. H. Grotberg (Ed.), Contemporary Psychology. Resilience for Today: Gaining Strength from Adversity (pp. 53-80). Praeger Publishers/Greenwood Publishing Group.

Saiki, C. S. (2014). Overview of Grounded Theory Approach. Keio SFC Journal, 14, 30-43.

Satou, T., \& Sukemune, S. (2009). A Trial for Standardization of the Resilience Scale: Development and Reliability/Validity Check of the S-H Resilience Scale (Part 1). The Japanese Journal of Nursing Research, 42, 45-52. 
Suzuki, A., \& Nakagomi, S. (2013). Change of Social Support Sought by Injured Athletes during Rehabilitation. Japanese Journal of Sport Psychology, 40, 139-152.

Tachiya, Y. (2018). The Relationship of Sport Mental Training and Psychosomatic Medicine in Psychological Supports for Elite Athletes. Japanese Journal of Psychosomatic Medicine, 58, 166-173.

Takekawa, T., Yamada, M., \& Yokozawa, T. (2017). The Psychological Competitive Ability of College Athletes. Bulletin of Asian Studies, No. 15, 45-51. 